\title{
RAPID SOLIDIFICATION OF CAST IRON
}

\author{
Elizabeth. P. Elenwa \\ Department of Chemical Engineering, School of Material Science, University of Leeds, UK \\ DOI: $10.31364 / S C I R J / v 7 . i 2.2019 . P 0219617$ \\ http://dx.doi.org/10.31364/SCIRJ/v7.i2.2019.P0219617
}

\begin{abstract}
The grey cast iron wasrapidly solidified by drop tube technique and different sample sizes obtained. The calculation results of the cooling rates of the grey cast iron samples shows that the maximum cooling rate obtained is $7280 \mathrm{~K} / \mathrm{s}$ in this experiment. The microstructure of the grey cast iron samples with different sizes were characterized using optical microscopy, scanning electron microscopy and $\mathrm{x}$-ray diffraction analysis. In the microscopic analysis, it was found that lower cooling rates promote graphite formation in grey cast iron. The microstructure of the grey cast iron bar (unetched) shows the most desired morphology and distribution of grey cast iron.The X-ray diffraction analysis shows the main peaks present in the samples and their experimental intensities. Peaks (011) and (101) were present in all the samples with (011) being the most intense peak. The theoretical intensities and the relative ratios of these peaks were estimated and presented in table 1 and 2 of this work. The solidification behaviour in drop tube technique is significantly affected by the size of the droplet which can generally determine the exact level of underccooling. The cooling rate in this process is estimated and their effect on the structural morphology of grey cast iron is discussed.
\end{abstract}

Keywords: Rapid solidification; Drop tube; Grey cast iron; cooling rate; Graphite flakes; Microstructure

\section{Introduction}

Rapid solidification has been known to produce non-equilibrium microstructures and some significant distinct results are novel crystalline or amorphous phases, grain size refinement and solid solubility extension (Wang and Wei 2000). Generally, rapid solidification is attained by employing rapid quenching methods, such as gas atomization, laser surface melting, melt spinning and splat quenching. The major principle behind these techniques is the rapid ejection of latent heat that has been accumulated. The disadvantage of these techniques is that the specimen or sample is normally small in one dimension, resulting to difficulty in directly observing nucleation and growth phenomena.

Among recent techniques like glass fluxing method, the drop tube method has become a popular one. Drop tube technique is appropriate for investigation in rapid solidification because bulk melt can be dispersed into tiny droplets in this technique. The advantage of this technique lies in two aspects. One, there will be significant reduction in the number of possible heterogeneous nuclei in single droplets. The second is that the tiny droplets can attain high cooling rates during containerless processing, leading to large undercooling and hence occurrence of rapid solidification. (Lavernia and Srivatsan 2009). Therefore, drop tube technique has been widely used in rapid solidification of cast iron.

Grey cast iron is a binary eutectic alloy obtained commercially by the addition of silicon to the Fe-C base system. It has numerous industrial applications because of its good castability, flexibility, cost effectiveness, wear resistance and wide range of attainable mechanical properties. Grey cast iron properties depend on the size, the amount and distribution of graphite flakes and the structure of the matrix. The common different types of flake graphite seen in the grey cast iron are shown in figure 1 as reported by Shah 2000. The objective of this work is to rapidly solidify grey cast iron using drop tube technique and to investigate the effect of cooling rate on the microstructure of grey cast bar (as received) and powders with different sizes. 

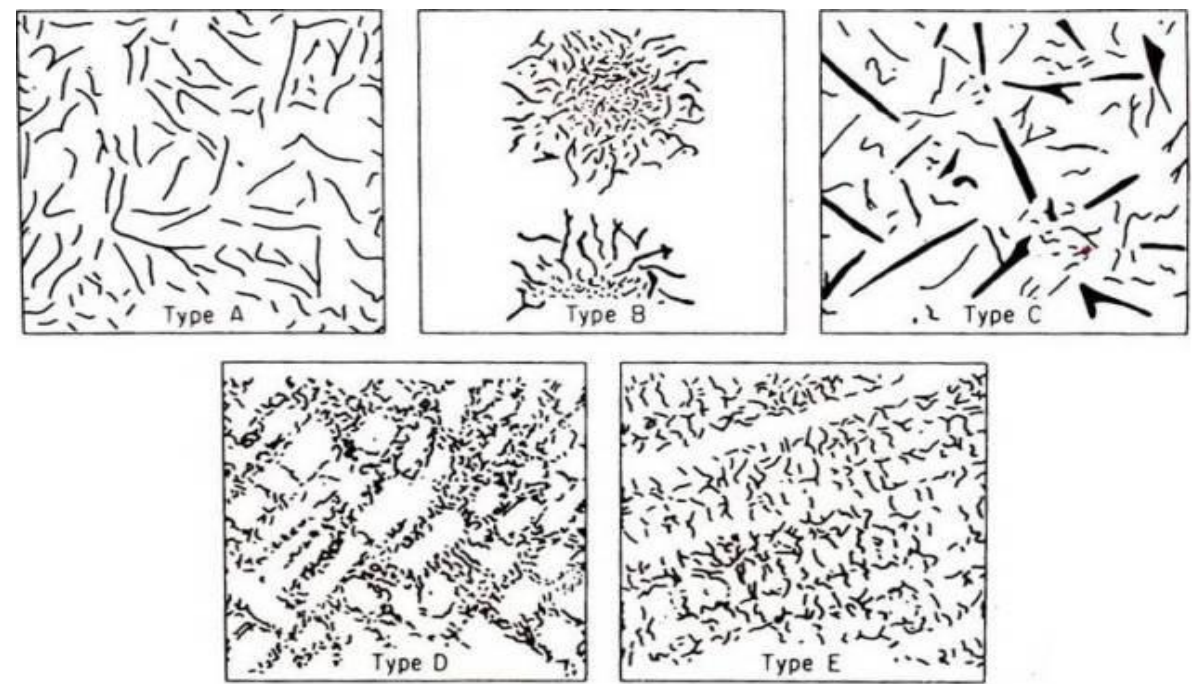

Figure 1:Graphite flake types. Type A: Uniform distribution, random orientation, Type B: Rosette groupings, random orientation, Type C: Superimposed flake sizes, random orientation, Type D: Interdendritic segregation, random orientation and Type E: Interdendritic segregation, preferred orientation (Shah 2000).

\section{Experimental}

\subsection{Drop Tube Technique}

The rapid solidification of grey cast iron was carried out in a $6 \mathrm{~m}$ micro gravity drop tube with nitrogen acting as the protective inert gas in the experiment. The schematic sketch of grey cast iron drop tubecore part is shown in Fig. 2.During the process of the experiment, the sample was first inserted into the crucible and then the basic parts were assembled together below the furnace as seen in figure 2(b), which was rooted onto the drop tube as shown in figure 2(a). During the process of evacuation, the system was filled to a pressure of $40 \mathrm{KPa}$ with dried $\mathrm{O}_{2}$ free $\mathrm{N}_{2}$ gas, having been previously flushed thrice with $\mathrm{N}_{2}$ and cleared to a pressure of $4 \times 10^{-3} \mathrm{~Pa}$ attributing to the integration of a mechanical rotary and turbo-molecular pump. After the supposed protective atmospheric conditions were generated, the turbo-pump was switched off. Then the alloy sample was heated by induction. As soon as the supposed temperature was attained, the gas store was pressurized with nitrogen (normally $3 \times 10^{5} \mathrm{~Pa}$ ) and then the melt sample was sprayed. After the system temperature dropped to room temperature, the final rapidly solidified particles were collected at the bottom of the drop tube.

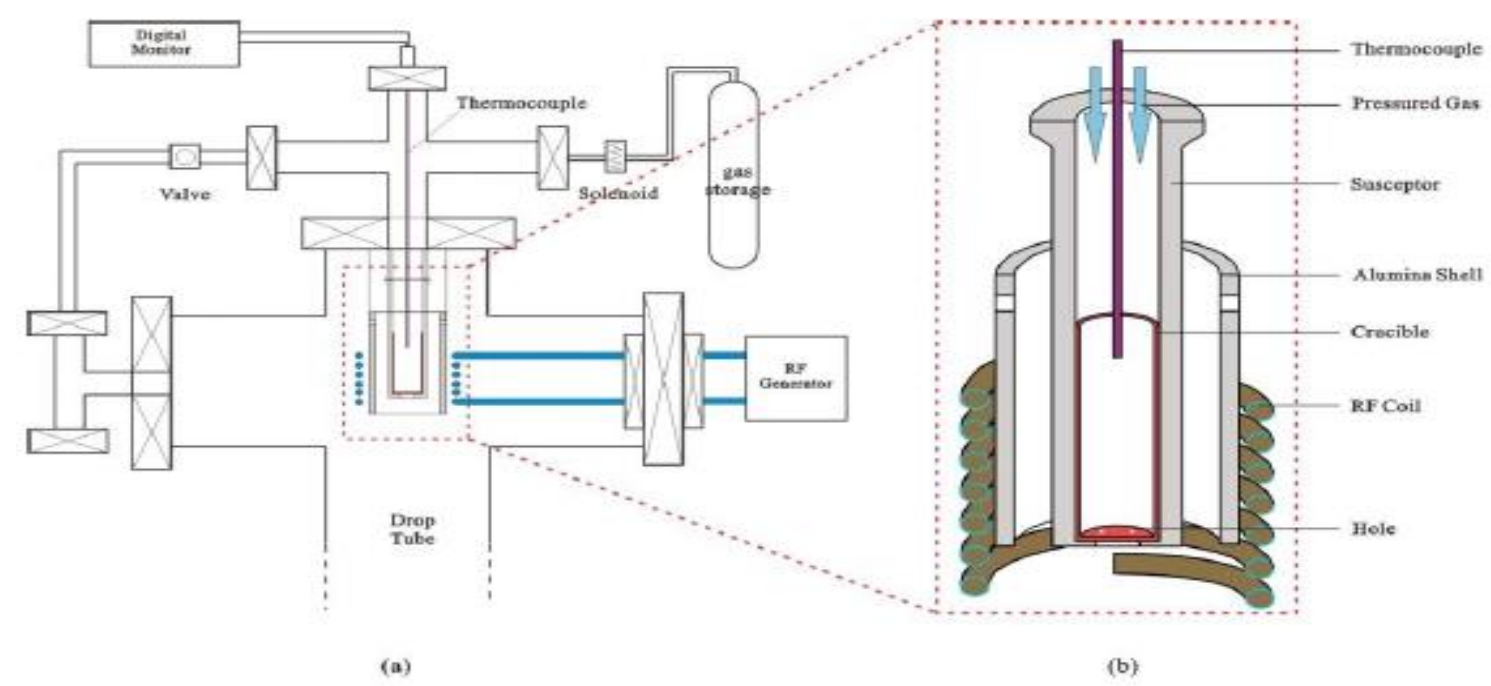

Figure 2:The assembly of the top furnace section of the drop tube. (b) The comprehensive layout of the red rectangular section in the left diagram (Biggs 2014) 


\subsection{Metallography Analysis}

After experiments, the solidified samples were mounted in a Bakelite resin, grinded, polished and etched with nital (a mixture of $98 \mathrm{~mL}$ ethanol and $2 \mathrm{~mL}$ nitric acid). The solidification microstructures were investigated using optical microscopy (OM), scanning electron microscopy (SEM) and x-ray diffraction (XRD) analyser.

\section{Results and discussions}

\subsection{Determination of cooling rates}

The cooling rate for the different grey cast iron samples was estimated using the correlation below (Mullis 2014):

$$
\frac{d T}{d t}=258.47 d^{-1.624}
$$

Where $\mathrm{dT} / \mathrm{dt}$ is the cooling rate in $\mathrm{Ks}^{-1}, \mathrm{~d}$ is the size (length) of the sample in $\mathrm{mm}$. Therefore,the cooling rate for the cast iron bar as received is $2 \mathrm{~K} / \mathrm{s}$, cast iron crucible residue is $95 \mathrm{~K} / \mathrm{s}$, cast iron powder size $850 \mu \mathrm{m}$ is $335 \mathrm{k} / \mathrm{s}$ and cast iron powder $106-150 \mu \mathrm{m}$ is $7280 \mathrm{~K} / \mathrm{s}$. Hence the maximum cooling rate obtained in this work is $7280 \mathrm{~K} / \mathrm{s}$ (powder size 106-150 $\mu \mathrm{m}$ ). Since the cooling rate in the cast iron as received bar differs from point to point on the surface, for simplicity purpose it was assumed that the cooling rate is the same on the surface $(2 \mathrm{~K} / \mathrm{s})$ as estimated using equation above.

\subsection{Microstructures}

The microstructure of the grey cast iron samples is presented in figure 3. Upon analysis of the grey cast iron samples microstructures, it became apparent that the samples conform to some common structural forms of grey cast iron. Figure $3 \mathrm{a}$, shows graphite flakes in random orientation in its matrix. The graphites appear as many irregular, extended and curved plates which gives grey cast iron its unique characteristic greyish fracture. This is similar to the reference (see figure 1) that shows the different microstructures common to grey cast iron. This type of structure is known as type A in the Foundrymen's Society (AFS) and American Society for Testing Materials (ASTM) standard specification A247. Figure 3b shows a similar structure as 3a (type A graphite flake). But the graphite flakes are tiny and compacted as compared to figure 3a. Looking at the estimated cooling rate it can be noticed that the cooling rate of the crucible residue is far higher than the cast iron bar. So, this trend is expected because as earlier stated, high cooling rate does not favour graphite formation in grey cast iron and vice versa.

Figure $3 \mathrm{c}$ shows a rather interesting structure, the graphite flakes are very tiny and in random orientation. This is expected because compared to figure $3 \mathrm{a}$ and $3 \mathrm{~b}$, the cooling rate is much higher. Figure $3 \mathrm{~d}$ shows a complete featureless homogenous phase. From experimental and literature review by Rivera, although not reported in this work, the featureless phase could be austenitic solid solution. The austenitic solid solution phase could be traced to the effect of manganese (Mn). Mn is known to be an austenite stabilizer which slows down graphitization. Another reason this effect may arise from the fact that the carbon dissolve in the matrix instead of precipitating out as graphite. A possible solution to this will be to further undercool the sample, this way the carbon will precipitate out as graphites. 


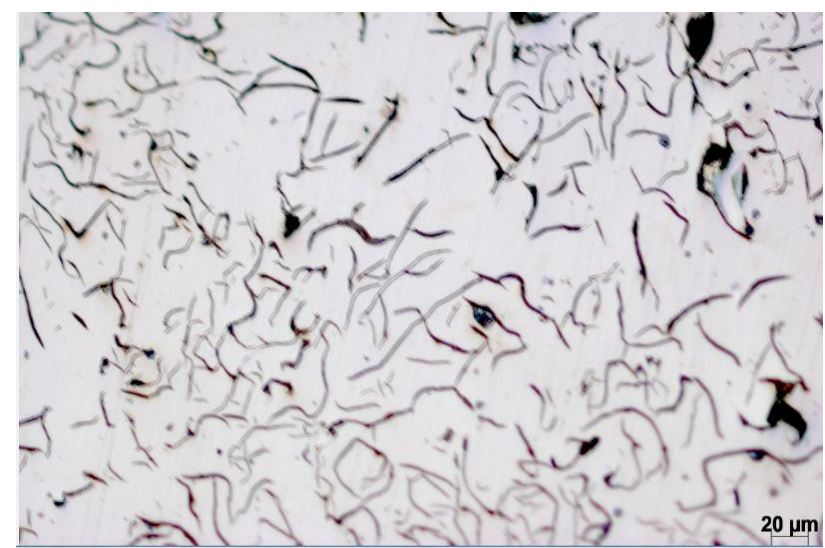

a

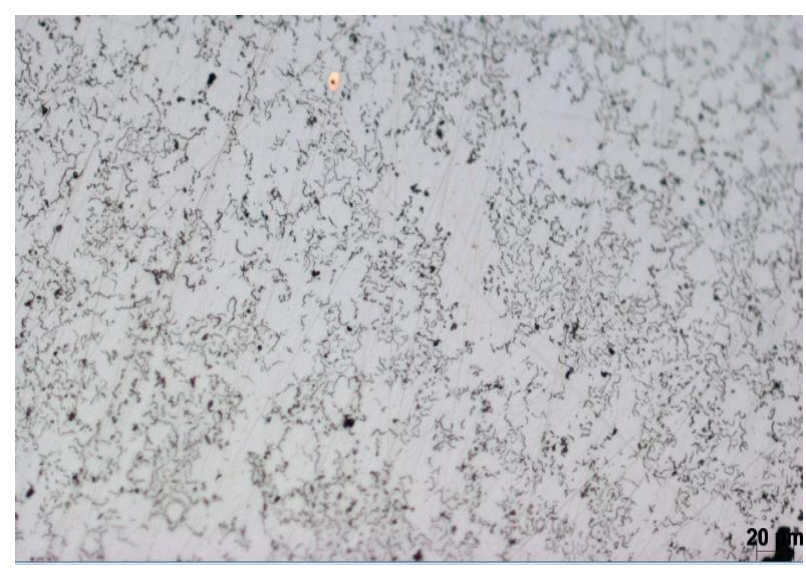

C

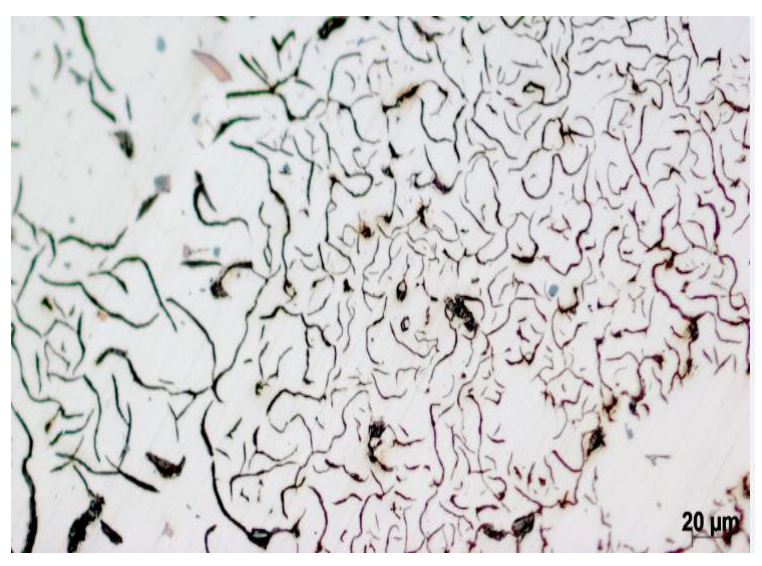

b

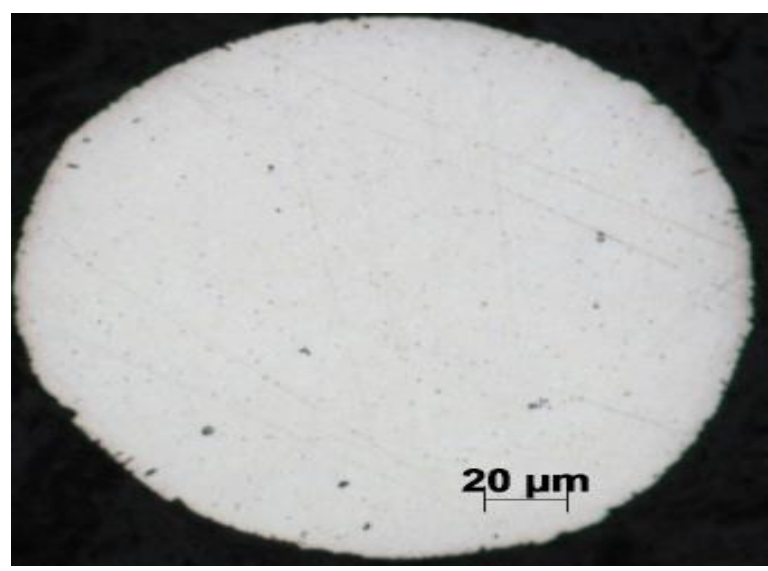

d

Figure 3: Optical micrograph microstructure of (a): Greycast iron bar as received, (b): grey cast iron crucible residue, (c): powder

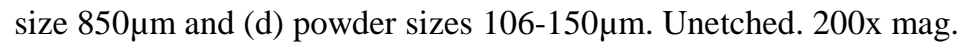




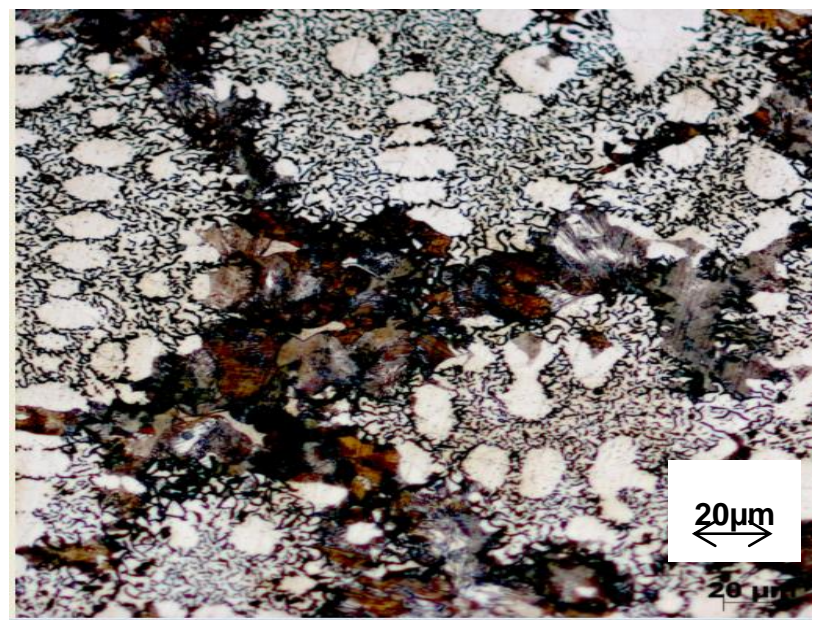

a

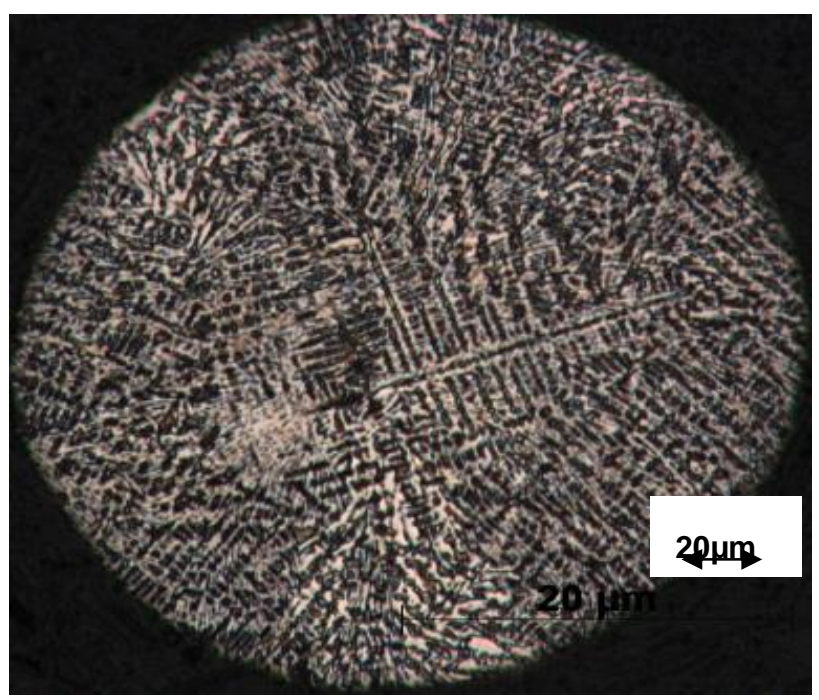

C

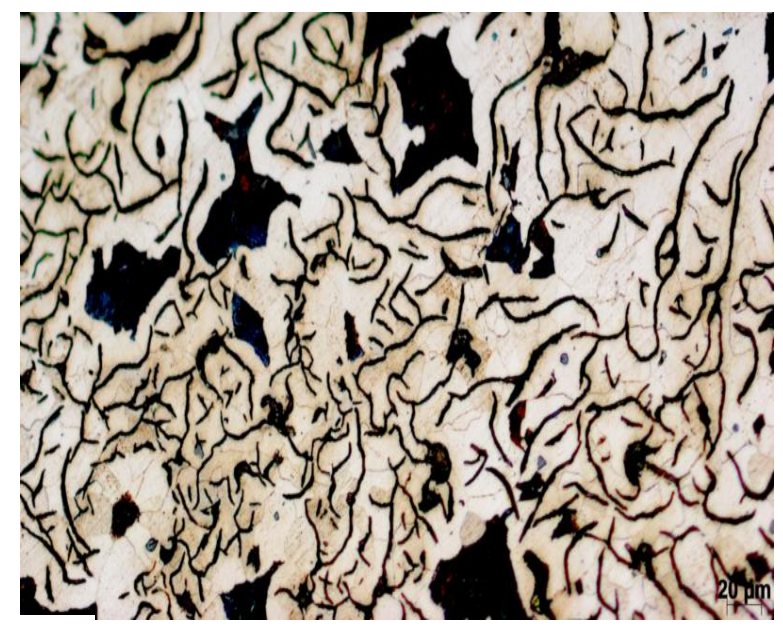

b

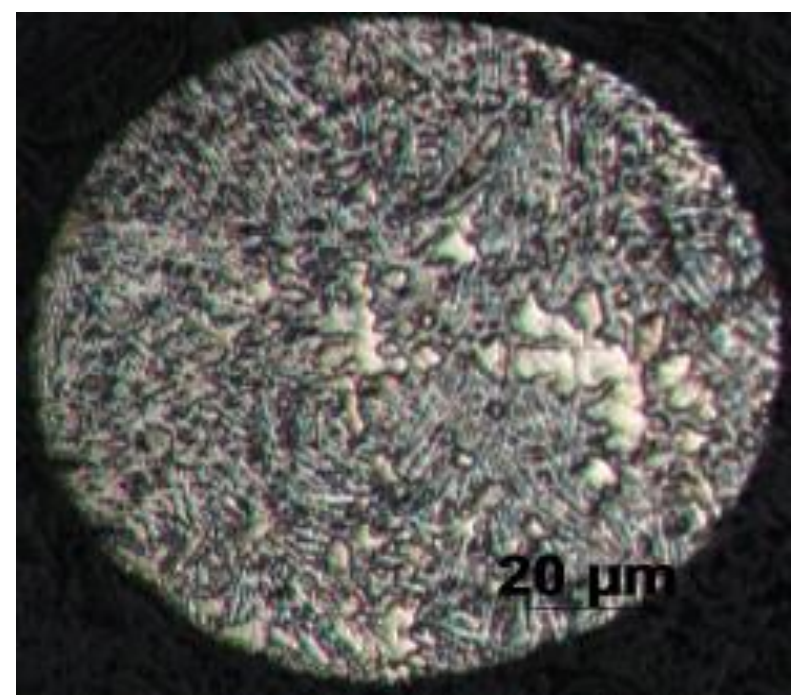

d

Figure 4: Optical micrograph microstructure of (a): Greycast iron bar as received, (b): grey cast iron crucible residue, (c): powder

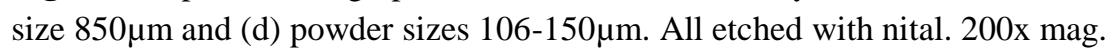

Figure 4 above shows the same samples as figure 3 but this time they were all etched with nital. Figure 4 a shows a similar structure of type B reported in figure1, the tiny graphite flakes are in rosette grouping and random orientation. This rosette structure is one of the most common forms of graphite flakes. Figure $4 \mathrm{~b}$ shows similar structure and also took the form of type A graphite flake. In figure 4c, a dendritic structure in form of a tree like structure can be seen forming with the effect of the nital. This tree like structure is one of the most frequently occurring morphology of metallic alloy when solidification takes place (Ghosh 2007). It can be concluded that etching shows different microstructure of the cast iron and this can be attributed to the chemical composition of the etchant used. This is expected because in literature, it is stated that chemical compositions affect the structures in grey cast irons. 




a

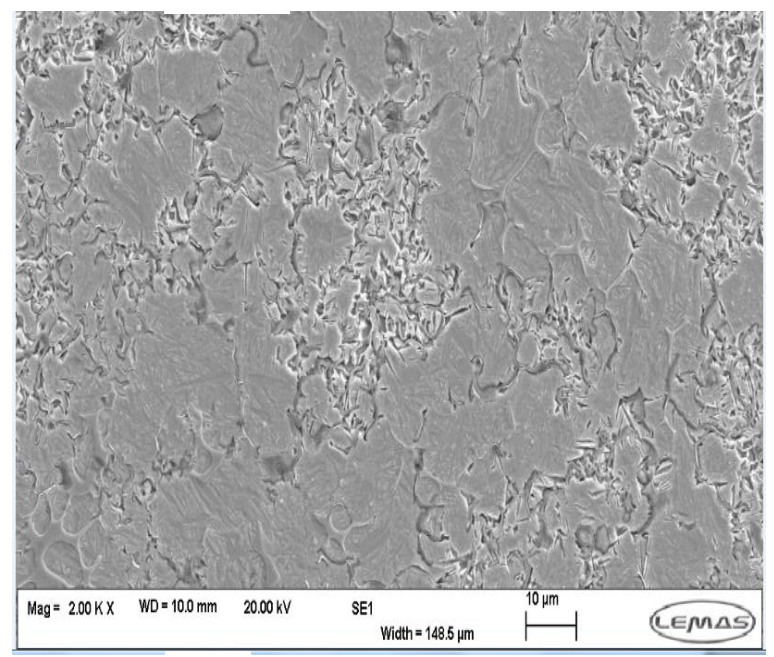

C

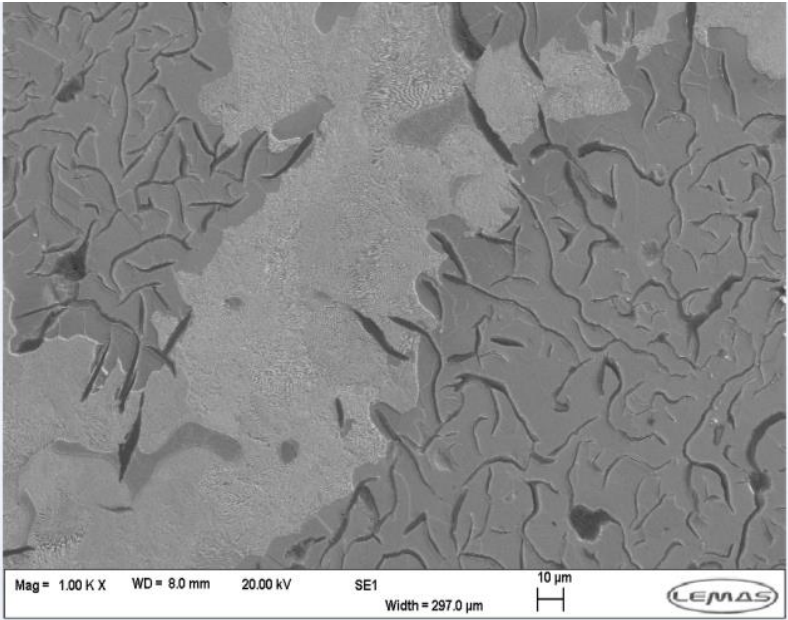

b

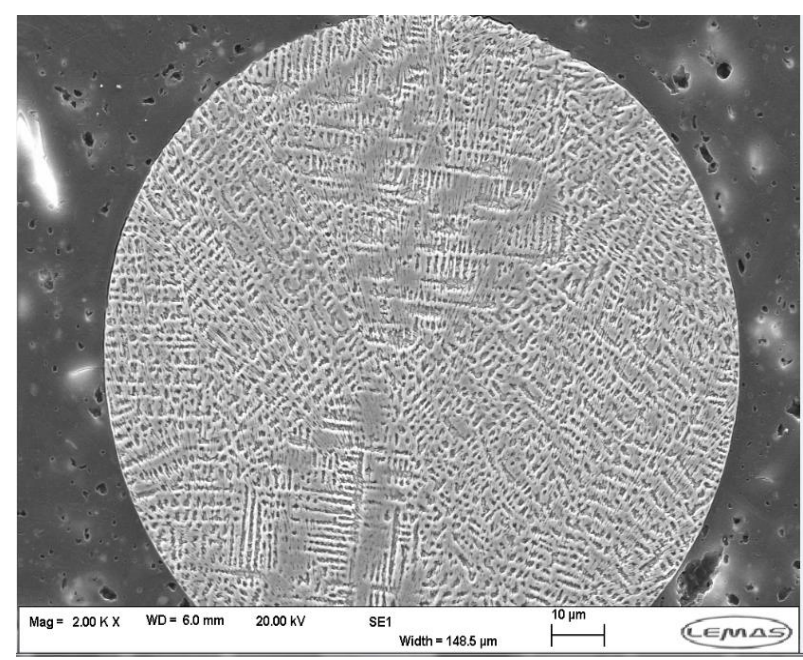

d

Figure 5: SEM micrograph micrograph microstructure of (a): Greycast iron bar as received, (b): grey cast iron crucible residue,

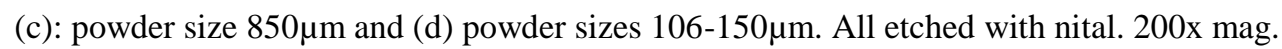

Figure 5 above is the SEM micrograph images of the grey cast iron samples. The SEM reveals details of the grain boundary and higher revolution of the grey cast iron graphite flakes. In figure 5a, the graphite flakes are more visible and the matrix clearly seen.The graphite flake is in uniform distribution and random orientation (type A graphite flake). Whereas, as compared to figure $4 \mathrm{a}$; the optical analysis result, the graphite flake is type B and very tiny. Figure 5b shows a similar structure as the optical analysis result infigure $4 \mathrm{~b}$. The only difference in figure $5 \mathrm{~b}$ is that the graphite flakes are detached from its matrix and widely spread in random orientation, whereas the graphite flakes in figure $4 \mathrm{~b}$ is compacted together. Figure $5 \mathrm{c}$ shows a different structure from the optical microscopy analysis (figure 4c). While the graphite flakes are not too visible, a rosette grouping of the flakes can be noticed in random orientation. Also, in figure 5d,interdendritic structures can be seen forming from the matrix in preferred orientation. An XRD analysis was also carried out to detect main peaks from the grey cast iron samples structure. The results of the XRD analysis ispresented in figure 6. In figure 6a only two peaks were detected and the intensity of the first peak is very high compared to the second peak. Only iron (Fe) was analysed in the cast iron bar as received sample. The recorded peaks are (011) and (101) with (011) being the most intense peak. In figure 6b (powder sizes 212-300 $\mu \mathrm{m}$ ), Fe3C is seen in the sample and four peaks were recorded. The peaks are (011), (101), (020) and (111). The experimental intensities for these peaks and their relative ratios are summarised in tables 1 and 2 


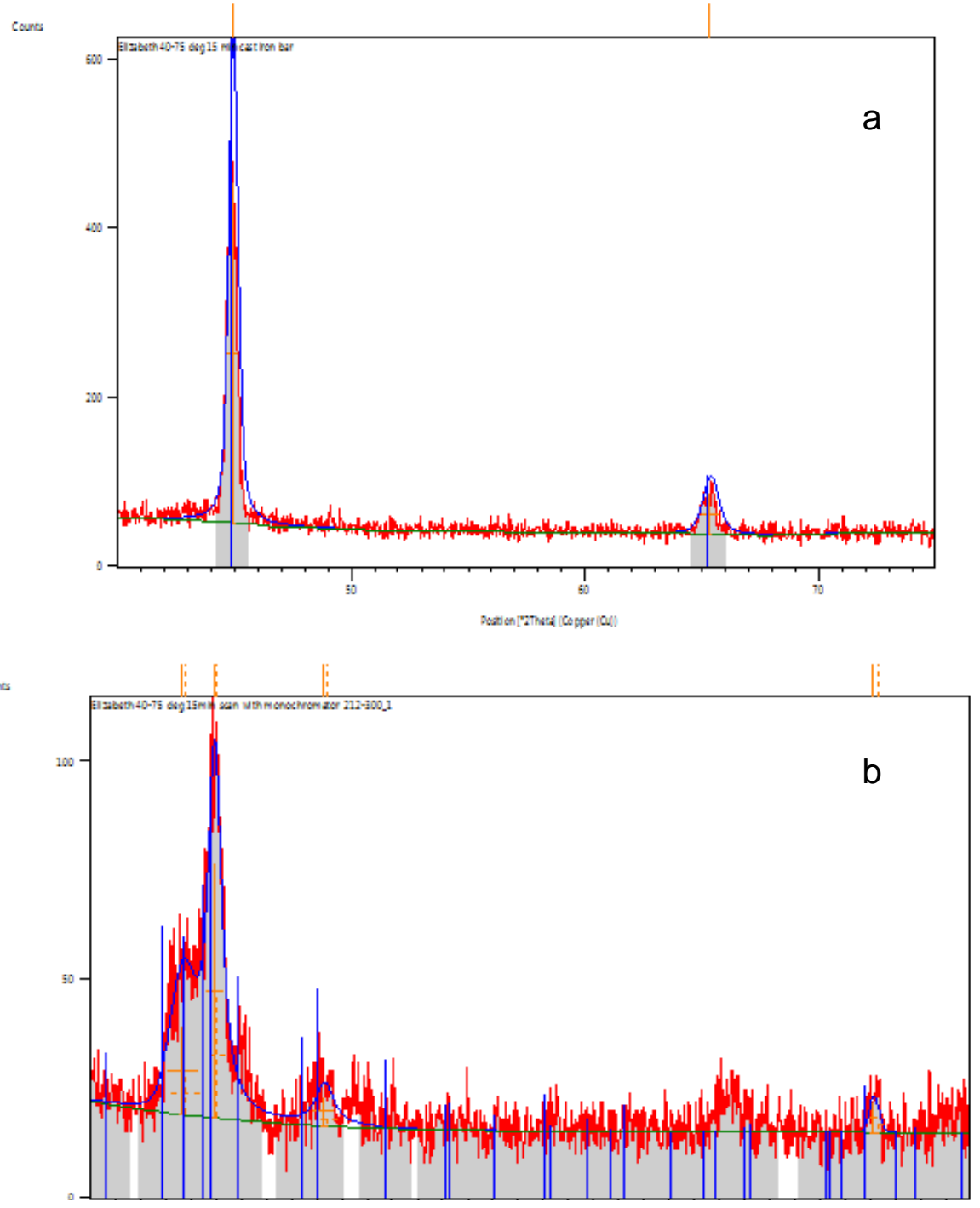

Table 1: Theoretical Intensities for cast iron bar (as received) Peaks and their Relative Ratios

\begin{tabular}{|l|l|l|}
\hline$\{$ hkl $\}$ & $\mathbf{R}_{\mathbf{h k l}}$ & $\left(\mathbf{R}_{\mathbf{h k}} / \mathbf{R}_{\mathbf{0 1 1}}\right) \times \mathbf{1 0 0}$ \\
\hline 011 & $316,783.12$ & 100 \\
\hline 101 & $118,562.32$ & 37 \\
\hline
\end{tabular}

Where $\{\mathrm{hkl}\}$ are the experimental intensities and $\mathrm{R}_{\mathrm{hkl}}$ are the theoretical ones (Klug and Alexander 1974). As the ratios of these values are important, they were estimated using the peak dependant factors.

Table 2: Theoretical Intensities for powder sizes 212-300 $\mu \mathrm{m}$ Peaks and their Relative Ratios

\begin{tabular}{|l|l|l|}
\hline$\{$ hkl $\}$ & Rhkl & $\left(\mathbf{R}_{\mathbf{h k}} / \mathbf{R 0 1 1}\right) \times \mathbf{1 0 0}$ \\
\hline 011 & $316,783.12$ & 100 \\
\hline 101 & $118,562.32$ & 37 \\
\hline
\end{tabular}




\begin{tabular}{|l|l|l|}
\hline 020 & $125,789.23$ & 40 \\
\hline 111 & $305,879.23$ & 97 \\
\hline
\end{tabular}

\section{Conclusions}

Based on the experimental results of the grey cast iron drop tube, the following conclusions were drawn:

(1). Grey cast iron was rapidly solidified by drop tube technique and different samples sizes were obtained

(2). Cooling rate was estimated for different grey cast samples and the maximum cooling rate estimated in this work is $7280 \mathrm{~K} / \mathrm{s}$.

(3). The result of the microscopic analysis shows that lower cooling rate promotes graphite formation in grey cast iron and vice versa.

(4). Dendritic structure and distribution are seen in the grey cast powder particle with smaller size

\section{References}

Lavernia, E.J., Srivatsan, T. S. (2009). The Rapid Solidification Processing of Materials: Science, principles, Technology, Advances, and Applications. Material Science, 1-5

Jacobson, L. A.; and McKittrick, J. (1994).Rapid Solidification Processing. Volume 11, Issue 8. A Journal Review, 1-3, 6-8

Klug, H. P.; Alexander, L.E. (1974).X-Ray Diffraction Procedures for Polycrystalline and Amorphous Materials. New York

Shah. K. P. (2000). The Hand Book on Mechanical Maintenance: Practical Maintenance

Wang, N., Wei, B., (2000). Rapid Solidification Behaviour of $\mathrm{Ag}-\mathrm{Cu}-\mathrm{Ge}$ Ternary Eutectic Alloy. Material Science \& Engineering

Yang, M.; Dai, Y.; Song, C.; Zhai, Q. (2010).Microstructure Evolution of Grey Cast Iron Powder by High Pressure Gas Atomization

Ghosh, S. (2007).Micros-Structural Characteristics of Cast Irons.National Metallurgical Laboratory. Jamshedpur

Rivera, G.L., Boeri, R.E., Sikora, J.A. (2004). Solidification of gray cast iron. Materials Science, 1-3

\section{Acknowledgement}

Special thanks to the Almighty God for the gift of life, strength, wisdom and understanding to carry out this work. Am grateful to Professor Andrew Mullis for his wonderful support and contributions and my parents Mr and Mrs Loveday Elenwa. 